SUPPORTING INFORMATION FOR:

\title{
Interactions of the C-terminal Truncated DEAD-box Protein DDX3X with RNA and Nucleotide Substrates
}

Anthony F. T. Moore ${ }^{1,2}$, Aliana López de Victoria ${ }^{2,3}$ and Eda Koculi*

${ }^{2}$ Department of Chemistry, University of Central Florida, Orlando, FL

${ }^{3}$ Present affiliation Bio-Rad Laboratories Inc., Hercules, CA

*Corresponding author. Department of Biology Johns Hopkins University, 144 Mudd Hall, 3400 N.

Charles Street, Baltimore, MD 21218, E-mail ekoculi1@jhu.edu, phone-410-516-7314, fax: 410-5165213

${ }^{1}$ Anthony F.T. Moore has passed away 


\section{SUPPORTING INFORMATION FIGURE CAPTIONS}

FIGURE S1. The amino acid sequence of the DDX3X construct used in this study. Selected features, as highlighted in the amino acid sequence: N-terminal domain (cyan); catalytic core (red); residues 545-582 of the C-terminal domain (green). The non-colored region is the His-tag and the TEV cleavage sites.

FIGURE S2. EMSA gels. Concentration of DDX3X construct increases from left-to-right. (A) RNA substrate A:A, in the absence of nucleotide; (B) RNA substrate A:A, in the presence of AMPPNP; (C) RNA substrate $\mathrm{B}: \mathrm{B}$, in the absence of nucleotide; (D) RNA substrate B:B, in the presence of AMPPNP; (E) RNA substrate $\mathrm{C}$, in the absence of nucleotide; (F) RNA substrate $\mathrm{C}$, in the presence of AMPPNP; (G) RNA substrate D:E, in the absence of nucleotide; (H) RNA substrate D:E, in the presence of AMPPNP. 
MHHHHHHSSGVDLGTENLYFQSMSHVAVENALGLDQQFAGLDLNSSDNQSGGSTASKGRYIPPHLRNREA TKGFYDKDSSGWSSSKDKDAYSSFGSRSDSRGKSSFFSDRGSGSRGRFDDRGRSDYDGIGSRGDRSGFGK FERGGNSRWCDKSDEDDWSKPLPPSERLEQELFSGGNTGINFEKYDDIPVEATGNNCPPHIESFSDVEMG EIIMGNIELTRYTRPTPVQKHAIPIIKEKRDLMACAQTGSGKTAAFLLP I LSQ IYSDGPGEALRAMKENC RYGRRKQYPISLVLAPTRELAVQIYEEARKFSYRSRVRPCVVYGGADIGQQIRDLERGCHLLVATPGRLV DMMERGKIGLDFCKYLVLDEADRMLDMGFEPQIRRIVEQDTMP PKGVRHTMMFSATFPKEIQMLARDFLI EYIFLAVGRVGSTSENITQKVVWVEESDKRSFLLDLLNATGKDSLTLVFVETKKGADSLEDFLYHEGYAC TS IHGDRSQRDREEALHQFRSGKSPILVATAVAARGLDISNVKHVINFDLPSDIEEYVHRIGRTGRVGN: GLATSFFNERNINITKDLLDLLVEAKQEVPSWLENMAYEHHYKG

FIGURE S1 
$\mathbf{A}$

[DDX3X]

unbound

C

[DDX3X]

bound

unbound

E

[DDX3X]

bound

unbound

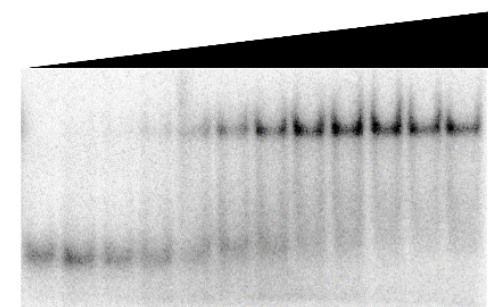

G

[DDX3X]

unbound

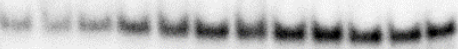

B

[DDX3X]

unbound

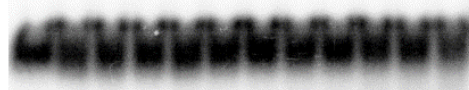

D

[DDX3X]

bound

unbound

boten -

$\mathbf{F}$

[DDX3X]

bound

unbound

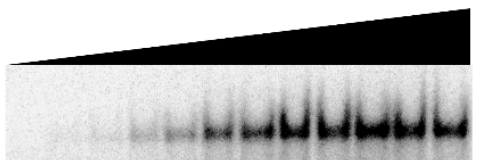

H

[DDX3X]

unbound

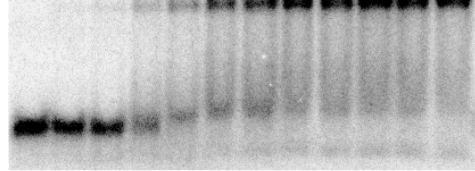

FIGURE S2 